\title{
Assessment of the severity of head injury
}

\author{
BRYAN JENNETT \\ From the University Department of Neurosurgery, \\ Institute of Neurological Sciences, Glasgow
}

SYNOPSIS Ranking of head injuries by severity is an essential part of clinical management, of prognosis, of treatment trials, and of legal assessment for compensation. Various methods of assessing severity are reviewed. No one scale is appropriate for all types of injury, or in all circumstances. A check list is provided which should enable every injury to be assessed; its use would facilitate comparison between individual cases of head injury, and between reports from different studies.

'Head injury' is used much more commonly than the several rubrics of the International Classification of Disease (ICD) which it encompasses; yet the term itself is not recognized as an entity in this classification. In practice it can embrace all degrees of severity from a symptomless bump to a blow which causes overwhelming brain damage. Yet what is necessary for an incident to qualify as a head injury is by no means self-evident. Such minimum requirements must indeed be arbitrary and may differ according to circumstances; they should therefore always be stated. For more serious head injuries it is important to have a practical scale of severity for the use of staff dealing with the early care of individual cases, as well as to facilitate communication between doctors and those concerned with outcome (relatives, employers, and lawyers). Without some such scale prognosis and the efficacy of alternative methods of management cannot be properly discussed, nor can epidemiological surveys be undertaken. Much of the confusion in the field of head injury arises from failure to describe severity in terms which can be generally understood and applied.

\section{INITIAL AND ULTIMATE SEVERITY}

What matters in a head injury is brain damage, whether actual or potential. In the majority of patients, however, the brunt falls on the scalp or skull, and there is only a possibility of intracranial complications. This accounts for classifications based on a posteriori evidence-deciding that the injury was not severe because the patient has made a good recovery. Contemporary concepts of the pathological basis of milder injuries have exposed the fundamental fallacy of this argument, in that mild concussion is now believed to produce permanent brain damage, albeit of a minor degree. For some practical purposes, however, it may be legitimate to construct a classification which depends on outcome, because this can take account of the net effect of the initial impact and of subsequent complications. This is certainly what matters to the patient and his family-not how hard he was hit, but what the consequences were. However, those concerned with management in the acute stage, whether dealing with individual patients or with evolving a strategy for hospitals or regions, must have a means of assessing severity at an early stage-before the consequences of the injury are known. As one of the main goals of head injury management is the prevention of complications, of what some have called the 'second accident', it is necessary to devise means of recognizing soon after injury what has already happened, in order to distinguish this from secondary events. Clinicians may feel a need to include a risk factor for specific complications as part of the categorization of the initial injury. But to do this would make the classification much more complex, involving probability statistics. 
Classification of severity, as a practical rather than a theoretical exercise, has therefore to serve different purposes. It seems inevitable that more than one scale will be necessary, according to circumstances. What then becomes important is to indicate clearly how these relate to each other. It is important also to use only terms which are descriptive and unambiguous; they should describe what is or what has been observed, rather than what has been deduced or guessed. In particular, attempts to describe clinical head injuries in respect of the presumed pathology should be avoided, because in most cases that pathology will never be known. Nothing has done more to confuse this field than continuing to classify cases according to the supposed occurrence of concussion, contusion, and laceration of the brain. No laboratory test is available which will measure brain damage or dysfunction, such as can be used to assess tissue damage in the lungs or the kidneys. That is why classification must rest on descriptive terms, with all the problems of definition which inevitably result. Wisely chosen and adequately validated, however, there is no reason why such terms should not become operationally useful.

\section{ADMINISTRATIVE CLASSIFICATION}

The only regularly collected statistics about head injuries in Britain apply to registered deaths and to patients admitted to hospital. These provide a readily available data source, and consequently statements about the prevalence of injuries of different severities are frequently based on them. For this reason they are discussed first, although, as will become clear, they are subject to serious limitations.

DEATH AS A MEASURE OF SEVERITY Deaths are commonly reported as due to 'head injury' on the basis of the cause stated on the death certificate. There is no formal restriction on the terms used on the certificates but presumably there is a convention which determines inclusion under 'head injury' by those responsible for assembling statistics from them. As $60 \%$ of deaths ascribed to head injury occur before there is time for admission to hospital (Field, 1976), the decision that head injury is in fact the cause of death often depends on the coroner and his pathologist.
While it is true in general that death is an indicator of the most severe injuries, it seems likely that a number of pre-hospital deaths ascribed to head injury are due to other causes, such as fracturedislocation of the cervical spine or multiple injuries; also that some deaths occurring in hospital are in patients in whom the impact injury was not overwhelming. A recent analysis of 151 injuries in a neurosurgical unit revealed that $38 \%$ had talked at some stage after injury (Reilly et al., 1975). Many of these had developed intracranial haematoma; others had suffered brain swelling and raised intracranial pressure, ischaemic/hypoxic brain damage, or meningitis. Had these complications not developed, many of these patients might have been regarded as having sustained only a minor or moderately severe head injury. Some of those who died before admission to hospital may likewise have suffered only minor brain damage, but have developed respiratory obstruction or circulatory failure due either to complications of their unconscious state or to a combination of multiple injuries. Clearly there are certain fallacies in using death as an indicator of the most severely injured.

HOSPITAL ADMISSION The fact of hospital admission is a frequently used measure of severity. No central statistics are kept for accident/emergency departments so there is no evidence to confirm whether even most of those admitted are definitely more severe than most of those sent home. There is no generally agreed admission policy in British hospitals, and practice varies from place to place. Only partly does this depend on variations in medical opinion; the availability of facilities may be a more important factor. If accident and emergency equipment and staffing are of a high standard admission rates may be kept relatively low; this may also happen if there are overnight beds in which patients are not recorded as inpatient admissions. About a third of patients admitted to hospital with head injury have another injury, and it may be this rather than the head injury which leads to hospital admission, or which determines the length of stay; this is another fallacy in regarding inpatient statistics as a reliable indicator of the severity of head injury.

Hospital admissions are ascribed to head injury according to which $I C D$ rubrics have been 
used by the hospital submitting data for central analysis. A recent survey of head injury statistics included the rubrics in Table 1 . Notice that this excludes wound, contusion, and haematoma of the scalp; but it includes fractures of the face bones, which in fact comprise $10 \%$ of the 140000 admissions annually under the above rubrics. The distribution of cases between these different rubrics may well reflect the custom of the personnel completing the forms; indeed, there is evidence that some hospitals return the majority of cases under N850 (concussion), others under N800 (fracture of skull), and yet others use N854 (intracranial injury unspecified). This is partly because the $I C D$ is unsatisfactory: some of the terms are not mutually exclusive and there is no recommendation as to which terms should take precedence in the event of more than one being applicable. Thus contusion, concussion, and skull fracture frequently coexist; so do cerebral laceration and subdural haematoma. Nonetheless, it is probably reasonable to regard those cases which are coded as N802 (facial fracture), N805 (concussion), and N854 (intracranial injury unspecified) as being less serious than those in the remaining seven rubrics; this categorization into severe and less severe injuries was used by Field in his analysis.

TABLE 1

RUBRICS IN ICD WHICH WERE TAKEN TO COVER 'HEAD INJURY’ IN THE FIELD REPORT (1976)

\begin{tabular}{ll} 
N800 & Fracture of vault of skull \\
N801 & Fracture of base of skull \\
N802 & Fracture of face bones \\
N803 & Other and unqualified skull fractures \\
N804 & $\begin{array}{l}\text { Multiple fracture involving skull or face } \\
\text { with other bones }\end{array}$ \\
N850 & $\begin{array}{l}\text { Concussion } \\
\text { N851 }\end{array}$ \\
N852 & $\begin{array}{l}\text { Cerebral laceration and contusion } \\
\text { habarachnoid, subdural, and extradural } \\
\text { mention of laceration or contusion) }\end{array}$ \\
N853 & $\begin{array}{l}\text { Other unspecified intracranial haemorrhage } \\
\text { following injury (without rnention of } \\
\text { cerebral laceration or contusion) }\end{array}$ \\
N854 & $\begin{array}{l}\text { Intracranial injury of other and unspecified } \\
\text { nature }\end{array}$ \\
\hline
\end{tabular}

DURATION OF HOSPITAL STAY The hospital inpatient inquiry provides information about duration of stay in hospital. The patients discharged within one to two days are likely to have suffered only a mild injury; it is less certain that those detained more than seven days necessarily have a severe injury, because discharge may have been delayed by an associated injury, or by the ready availability of beds. Nonetheless it will be true in general that severity of the head injury will likely be the main difference between groups of patients with these contrasting durations of hospital stay.

PATIENTS NOT ADMITTED TO HOSPITAL Information about these cases is available only from special, limited studies from which it is difficult to generalise. Although as a group it is fair to regard these patients as less severely injured than those admitted, there are many exceptions. As already mentioned, differences in admission policy or the availability of inpatient facilities may account for a considerable overlap in the severity of patients discharged from casualty and those admitted for 24 hours between different areas. Field (1976) has adduced evidence that most of the increase in inpatient admissions for head injuries over recent years is accounted for by a greater readiness to admit mildly injured patients; in terms of $I C D$ rubrics the increase is almost wholly accounted for by N854 (unspecified intracranial injury). As would be expected, the classification of severity by administrative criteria is suitable only for studies on large populations. In assessing severity in individual patients none of these criteria, not even death, is reliable as an indicator of the initial severity of the head injury; nor even of the net effect of primary and secondary brain damage, because a considerable number of deaths are ascribed to extracranial complications or to the effects of multiple injuries.

\section{INITIAL CLINICAL ASSESSMENT}

Most of the 140000 patients admitted each year to British hospitals are discharged in 24 to 48 hours. There are probably four times as many patients as this seen in accident and emergency departments who are sent home. Only a tiny proportion of these mildly injured patients develop serious complications and most are never 
seen again. Unless assessment is made soon after presentation there will be no other opportunity; and in most cases a decision about severity is what decides the course of action to recommend.

Two features stand out as dominant in the initial assessment of head injury. One is whether there is, or has been, alteration of consciousness; the other, whether there is a skull fracture. One is indicative of brain damage, the other of bone damage; although many patients have both, the two are poorly correlated. Either alone is usually taken as a criterion for admission to hospital and, because of this, a premium is put on determining when one or the other can be demonstrated.

ALTERED CONSCIOUSNESS A useful and practical distinction to make soon after injury is whether or not the patient is talking. If he is, the question is whether he is orientated in time and space, and is apparently rational. If he is, a further question is whether he has been so continuously since the accident, or whether there was impaired consciousness immediately after injury. Witnesses may report that he was for a time unconscious or confused; but if there are none, or if they report that he was apparently never unconscious, it is important to ascertain from the patient himself whether he can clearly recollect the accident and everything since then. If he cannot, and has a period of post-traumatic amnesia even of a few minutes, then he must be judged to have sustained some brain damage, however slight. Many would label this state concussion-that is, the state of brief unconsciousness or being dazed, with subsequent amnesia for the impact and immediately after it. It used to be part of the definition of concussion, as proposed by Trotter in 1924, that there was no structural brain damage and that there were no sequelae. Recent pathological investigations on patients who have died of other conditions soon after recovery from concussion have revealed that there are widespread structural lesions in the brain-albeit on a small scale (Oppenheimer, 1968); these suggest tearing of axons in the brain stem and subcortical white matter of the cerebral hemisphere. That even mild concussion leaves a legacy of permanent brain damage is also indicated by the finding that the effects of repeated concussion are cumulative (Gronwall and Wrightson, 1974); a striking example of this is provided by the fate of boxers who sustain repeated concussion (Corsellis et al., 1973).

In the patient who is not talking, other tests of responsiveness are required to assess the level of brain functioning. If he will also not obey commands and his eyes are closed he can be said to be in coma. In that event, the depth and durarion of coma will provide a good measure of the degree of diffuse damage sustained (vide infra).

SKULL FRACTURE A fracture is evidence of a certain degree of violence dealt to the skull, and so by implication to the brain. However, it is not uncommon to find fracture in patients who have never had impairment of consciousness; nor is it unusual to have serious brain damage without a fracture. In one consecutive series of 154 surviving head injuries with more than 24 hours PTA (vide infra) only $46 \%$ had a fracture (Jennett, 1975); and in a series of 151 fatal head injuries from a neurosurgical unit there were $20 \%$ without a fracture (Adams, 1975). It is depressed fractures which present the most striking disparity between brain damage and impairment of consciousness; thus $26 \%$ of 964 patients surviving depressed fracture had no initial loss of consciousness (Jennett, 1975). Most of these were compound fractures, many with the dura? torn and some with brain tissue oozing through the wound. The discrepancy between this and the immediate, if brief, loss of consciousness which is such a constant accompaniment of acceleration-deceleration injury is explained by the nature of the brain damage-focal under a depressed fracture, and diffuse with concussion.

It is relatively uncommon for a fractured skull to be recognizable on clinical grounds alone. Certainly basal fractures may declare themselves by signs such as CSF leakage from the nose or ears, bilateral orbital haematoma, or retroauricular (mastoid) haematoma. A depressed fracture may be obvious by reason of a dent in the skull contour or the appearance in a scalp wound of CSF or brain or bone fragments. However, these are all relatively unusual. The significance of a skull fracture is frequently debated, in relation to the need for carrying out radiography soon after injury. The finding of a skull fracture is of most significance in the patient who is otherwise relatively well, and in whom the fracture may provide the only definite evidence 
that significant violence has been done to the head; it may alert the clinician to the possibility of complications, such as intracranial haematoma or infection. These are uncommon events, but they are distinctly rare in patients without a skull fracture. Therefore it remains rational to recognize that patients who otherwise appear to have been trivially injured, but who have a fracture, are more severely affected than those who do not. It is in patients who have other obvious evidence of brain damage that the presence of a fracture is less significant, although even in them the location and type of fracture may influence management.

\section{INJURY SCALES FOR CRASH RESEARCH}

American workers concerned primarily with quantifying overall injury and its relation to the tolerance of the human body to various forces generated in automobile crashes have evolved an 'Abbreviated Injury Scale'. This recognizes six grades of injury (Table 2), with death separately recorded and whether this occurs within 24 hours of injury or later. More recently this same group of workers has proposed a more elaborate classification, the 'Comprehensive Injury Scale' (States et al., 1974). This provides for grading within each of the abbreviated categories; moreover, it has been suggested how this might be applied to injuries in different bodily regions in respect of energy dissipation and threat to life (Table 3).

TABLE 2

ABBREVIATED INJURY SCALE (AS APPLIED TO HEAD INJURY)*

\begin{tabular}{ll}
\hline & Head and neck \\
\hline Severity code & Severity category \\
\hline 1 & Minor \\
2 & Moderate \\
3 & Severe (not life-threatening) \\
4 & $\begin{array}{l}\text { Severe (life-threatening, survival } \\
\text { probable) }\end{array}$ \\
5 & $\begin{array}{l}\text { Critical (survival uncertain) } \\
\text { Maximum severity injuries (currently } \\
6\end{array}$ \\
\hline
\end{tabular}

*Condensed from States et al., (1974).
TABLE 3

QUANTITATION TERMINOLOGY FOR INJURY SCALING*

\begin{tabular}{|c|c|c|}
\hline Criteria & Code & Severity \\
\hline ED (energy dissipation) & $\begin{array}{l}1 \\
2 \\
3 \\
4 \\
5\end{array}$ & $\begin{array}{l}\text { Little or none } \\
\text { Minor } \\
\text { Moderate } \\
\text { Major } \\
\text { Maximum }\end{array}$ \\
\hline TL (threat to life) & $\begin{array}{l}1 \\
2 \\
3 \\
4 \\
5\end{array}$ & $\begin{array}{l}\text { None } \\
\text { Minor } \\
\text { Moderate } \\
\text { Severe (serious) } \\
\text { Maximum }\end{array}$ \\
\hline PI (permanent impairment) & $\begin{array}{l}1 \\
2 \\
3 \\
4 \\
5\end{array}$ & $\begin{array}{l}10-20 \% \\
21-40 \% \\
41-60 \% \\
61-90 \% \\
91-100 \%\end{array}$ \\
\hline TP (treatment period) & $\begin{array}{l}1 \\
2 \\
3 \\
4 \\
5\end{array}$ & $\begin{array}{l}1-2 \text { weeks } \\
3-8 \text { weeks } \\
2-6 \text { months } \\
6-12 \text { months } \\
>12 \text { months }\end{array}$ \\
\hline IN (incidence) & $\begin{array}{l}1 \\
2 \\
3 \\
4 \\
5\end{array}$ & $\begin{array}{l}\text { Unusual } \\
\text { Occasional } \\
\text { Common } \\
\text { Very common } \\
\text { Most frequent }\end{array}$ \\
\hline
\end{tabular}

*Comprehensive Injury Scale (States et al., 1974).

MISSILE INJURIES Military surgeons dealing with acute management, and neurologists concerned with the late effects of missile injuries, have devised fairly precise means of documenting these. The extent of the brain wound can often be deduced from operative findings, sometimes supported by radiological evidence of metal or bone fragments. From this evidence it is relevant to record the location and depth of the brain lesion and a scale based on this data has been found useful for these particular types of injury. As already indicated in discussing the different effects of diffuse and local injury on loss of consciousness, some of these injuries may be quite extensive without prolonged (or even any) loss of consciousness; in other cases there is loss of consciousness and post-traumatic amnesia. According to the location of the injury there may be focal CNS signs.

COMPLICATIONS AS EVIDENCE OF SEVERITY These are of most significance when a patient who initially appeared not to be severely injured suffers a secondary event, which changes the 
situation into a serious one, even if only temporarily or potentially. The most common and most clear-cut are early post-traumatic epilepsy, intracranial haematoma, and intracranial infection. Less easy to define are the effects of secondary brain swelling, often associated with contusions, and sometimes with a specific incident such as respiratory obstruction; or of hypotension and hypoxia, often associated with extracranial injuries or complications. That a significant proportion of injured who die in a neurosurgical unit have talked at some time since injury has already been mentioned; neuropathological examination of these cases reveals that in some the brain has sustained minimal impact damage (Reilly et al., 1975). Are these to be regarded as mild head injuries, or as severe because they proved fatal? Certainly there would seem need to distinguish between injuries which are overwhelmingly severe by virtue of impact injury, and those which become serious only secondarily. On the other hand it is confusing to speak of complicated and uncomplicated injuries, as a measure of severity; the patient with severe initial damage who remains in a persistent vegetative state (vide infra) would, by this classification, be uncomplicated-yet this is the most severe injury compatible with survival.

\section{DURATION OF ALTERED CONSCIOUSNESS}

It is almost half a century since Symonds (1928) first suggested that the duration of unconsciousness might be used as a measure of the degree of cerebral damage after a 'closed' head injury. This last term would now be interpreted as meaning acceleration/deceleration injury, the type which causes diffuse brain damage; as has already been emphasized, focal brain damage may be extensive without causing impairment of consciousness. The duration of altered consciousness after injury can be estimated from observation of the changing conscious state at the time, or it can be assessed retrospectively by the length of the post-traumatic amnesia (PTA).

Considerable confusion persists about how to assess coma, how deep it has been and how long it has lasted. We have published a critique of this, together with a practical scale (Table 4) which has been widely adopted (Teasdale and Jennett, 1974). Three aspects of responsiveness are
TABLE 4

GLASGOW COMA SCALE*

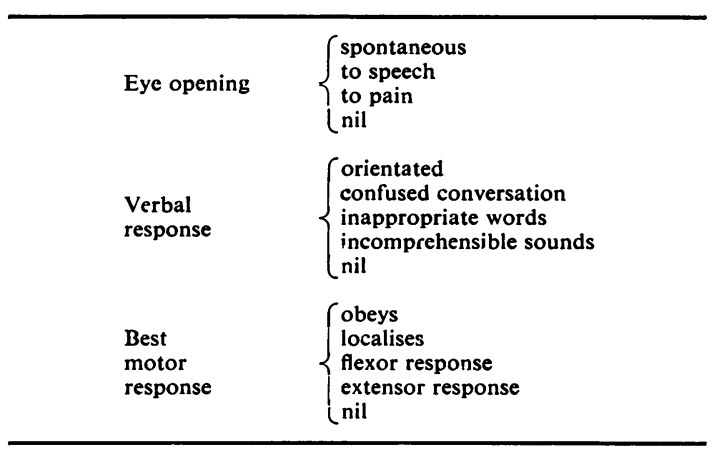

*Teasdale and Jennett (1974).

recorded-whether the eyes open, what verbal behaviour occurs, and motor activity. Each of these is separately assessed, so as to allow foro practical difficulties which can occur-when the eyes are too swollen to open or speech is pre-ब vented by intubation or a tracheostomy; for this reason a series of levels of coma is deliberately avoided, and the patient's state simply describedo by his place on each of the three scales (or as many as can be assessed). This 'Glasgow Coma? Scale' has been subjected to formal observererror study in different countries, including nonEnglish speaking observers, and has been found to be reliable (Teasdale et al., 1974).

It was not long after Symonds's proposal that Ritchie Russell (1932), after describing the stages of recovery of consciousness after a head injury, concluded that 'the patient's subsequent memory of when he woke up provides a not inaccurate indication of when consciousness returned.' In a range of different studies since then the duration of PTA has been shown to correlate closely with several other clinical features of injury, which reflect severity (Jennett, 1976). These include the presence of signs of brain damage, the occurrence of certain complications, the degree of ultimate recovery, both physical and mental, and the time for return to normal activity. The Lancet concluded in 1961 that the PTA was 'the best yardstick we have' for measuring the severity of blunt head injury. Its signal practical advantage over alternative measures is that it can be estimated by a doctor seeing the patient for the first 
TABLE 5a

PTA

\begin{tabular}{ll}
\hline$<5 \mathrm{~min}$ & Very mild \\
$<1 \mathrm{hr}$ & Mild \\
$1-24 \mathrm{hr}$ & Moderate \\
$1-7$ days & Severe \\
$>7$ days & Very severe \\
$>4$ weeks & Extremely severe \\
\hline
\end{tabular}

time at an interval after injury, who need not rely on witnesses of the early stages, nor on records made at that time.

In spite of this, PTA is seldom used in Britain outside of the Oxford school, which Ritchie Russell himself influenced; and in North America or continental Europe almost never. This reluctance to adopt such a useful method may be due to the belief that it is in practice difficult to assess the PTA. However, experience teaches that in most cases it is possible to estimate the duration within the broad time spans which Ritchie Russell originally suggested, and which have subsequently been equated with different degrees of severity (Table 5a). It is often possible to recognize the end of PTA when it happens, because it corresponds with the disappearance of confusion. The disparity between the duration of PTA and the time when the patient first began to talk is often striking. It is common to find both doctors and the patient's family referring to the end of coma as when the patient started to talk. When this occurs only 24 to 36 hours after injury, however, the PTA is usually of several days' duration; if talking is delayed for a week PTA commonly lasts a month or more. Evans et al. (1976) have observed that PTA is often about four times as long as the interval to first speech. In a series of severe head injuries, defined as coma lasting at least six hours, over $90 \%$ of survivors had PTA exceeding seven days; in these severe injuries outcome was clearly correlated with the duration of PTA (Table 5b) (Jennet et al., 1976).

\section{OUTCOME AS A MEASURE OF SEVERITY}

The ultimate degree of recovery after head injury is sometimes used to decide retrospectively whether or not the initial brain damage was
TABLE 5b

RELATION BETWEEN OUTCOME AND DURATION OF PTA

\begin{tabular}{lcccc}
\hline $\begin{array}{c}\text { PTA duration } \\
\text { days }\end{array}$ & $n$ & $\begin{array}{c}\text { Severe } \\
\text { disability } \\
(\%)\end{array}$ & $\begin{array}{c}\text { Moderate } \\
\text { disability } \\
(\%)\end{array}$ & $\begin{array}{c}\text { Good } \\
\text { recovery } \\
(\%)\end{array}$ \\
\hline$<7$ & 11 & & 9 & 91 \\
$7-14$ & 27 & & 26 & 74 \\
$15-28$ & 38 & 2 & 45 & 53 \\
$>28$ & 63 & 32 & 57 & 11 \\
\hline
\end{tabular}

severe or not. The original definition of concussion, which implied that no structural damage had occurred to the brain, included the condition that the injury was followed by no sequelae. It is now realized that even brief unconsciousness is probably always associated with some degree of brain damage, traces of which are, in fact, permanent; also that patients who have suffered marked brain damage, such as contusions or life-threatening haematomas, can make an apparently complete recovery. The qualification 'apparently' is necessary because different criteria can be used in the assessment of recovery; there may be considerable discrepancies between the patient's own assertion that he is fully recovered, the comments of his family or friends-who may report changes in personality or behaviour of which the patient is unaware-and the formal assessment of psychologists administering a battery of tests. Indeed, it is now increasingly recognized that many patients who have made a good physical recovery may have considerable mental sequelae, particularly in the field of defective memory or personality change, if these are specifically sought. Such abnormalities are consistently found in patients who have PTA exceeding three weeks (Bond, 1975). An outcome scale (Table 6) has been described which enables surviving patients to be classified into four categories, according to the overall social outcome (Jennett and Bond, 1975). Clearly those who are vegetative, or severely or moderately disabled can be regarded as having suffered brain damage of differing and graded degrees. What would, however, be misleading would be to regard those who have made a good recovery as having necessarily suffered only a mild injury. 
TABLE 6

GLASGOW OUTCOME SCALE*

\begin{tabular}{ll}
\hline Dead & - \\
$\begin{array}{l}\text { Persistent } \\
\text { vegetative } \\
\text { state }\end{array}$ & $\begin{array}{l}\text { Sleep/wake } \\
\text { non-sentient }\end{array}$ \\
$\begin{array}{l}\text { Severely } \\
\text { disabled }\end{array}$ & $\begin{array}{l}\text { Conscious but } \\
\text { dependent }\end{array}$ \\
$\begin{array}{l}\text { Moderately } \\
\text { disabled }\end{array}$ & $\begin{array}{l}\text { Independent } \\
\text { but disabled }\end{array}$ \\
Good recovery & $\begin{array}{l}\text { May have mild } \\
\text { residual }\end{array}$ \\
\hline
\end{tabular}

*Jennett and Bond (1975).

\section{CONCLUSION}

It is clear that no one method of assessing severity is appropriate for all types of head injury. However, every head injury can be described by reference to as many as possible of the features discussed here and listed in Table 7. The description should always include reference to duration of coma and PTA, and should distinguish initial severity from complications and sequelae. For example:

1. Uncomplicated injury without fracture, prolonged coma followed by persistent vegetative state.

2. Compound depressed fracture without initial coma or PTA; complicated by brain abscess; permanent hemiplegia and recurring epilepsy.

3. Injury with linear fracture, coma for three days, acute subdural haematoma, PTA 12 days, good recovery.

TABLE 7

MEASURES OF SEVERITY

\begin{tabular}{ll}
\hline Initial features & $\begin{array}{l}\text { conscious state } \\
\text { fracture } \\
\text { CNS signs }\end{array}$ \\
Complication & $\begin{array}{l}\text { epilepsy } \\
\text { haematoma } \\
\text { meningitis }\end{array}$ \\
Duration & $\begin{array}{l}\text { coma } \\
\text { PTA }\end{array}$ \\
Sequelae & $\begin{array}{l}\text { physical } \\
\text { mental }\end{array}$ \\
\hline
\end{tabular}

This should be used as a check list, and as many of these measures used as possible rather than regarding them as exclusive alternatives.
Notice that no adjectives of quality are used. Whether it is useful to try to encapsulate complex series of events such as these in a single term, such as mild, moderate, or severe, is doubtful. When comparing different head injury populations it may be necessary to set limits of severity; several recent studies have been based on patients in coma for at least six hours; or with PTA for at least 24 hours. Certainly if those interested in head injury were to agree always to declare information about as many as possible of the items identified here as useful measures of severity, it would soon become easier to compare the reports of different workers, and to define severity in terms which are generally intelligible.

\section{REFERENCES}

Adams, J. H. (1975). The neuropathology of head injuries. In Injuries of the Brain and Skull, vol. 23 of Handbook of Clinical Neurologv, pp. 35-65. Edited by P. J. Vinken and G. W. Bruyn. North-Holland Amsterdam.

Bond, M. (1975). Assessment of the psychosocial out come after severe head injury. In Outcome of Severe Damage to the Central Nervous System. Ciba Foundation Symposium 34 (new series) pp. 141-157. Elsevier Amsterdam.

Corsellis, J. A. N., Bruton, C. J., and Freeman-Browne, D. (1973). The aftermath of boxing. Psychological Medicine, 3, 270-303.

Evans, C. D., Bull, C. P. I., Davenport, M. J., Hall, P. M., Jones, J., Middleton, F. R. I., Russell, G., Stitchbury, J. C., and Whitehead, B. (1976). Rehabilitation of the brain damaged survivor. Injury. (In press).

Field, J. H. (1976). A Study of the Epidemiology of Head Injury in England and Wales. Department of Health and Social Security: London.

Gronwall, D., and Wrightson, P. (1974). Delayed recovery of intellectual function after minor head injury. Lancet, 2, 605-609.

Jennett, B. (1975). Epilepsy after Non-missile Head Injuries. 2nd edn. Heinemann: London.

Jennett, B. (1976). Post-traumatic amnesia as an index of head injury severity. (In preparation).

Jennett, B., and Bond, M. (1975). Assessment of outcome after severe brain damage. A practical scale. Lancet, 1, 480-484.

Jennett, B., Teasdale, G., Braakman, R., Minderhoud, J., and Knill-Jones, R. (1976). Predicting outcome in individual patients after severe head injury. Lancet, $\mathbf{1}$, 1031.

Lancet (1961). The best yardstick we have. Lancet, 2, 1445-1446. 
Oppenheimer, D. R. (1968). Microscopic lesions in the brain following head injury. Journal of Neurology, Neurosurgery, and Psychiatry, 31, 299-306.

Reilly, P. L., Graham, D. I., Adams, J. H., and Jennett, B. (1975). Patients with head injury who talk and die. Lancet, 2, 375-377.

Russell, W. R. (1932). Cerebral involvement in head injury. Brain, 55, 549-603.

States, J. D., Huelke, D. F., and Hames, L. H. (1974). Revision of the abbreviated injury scale (AIS). American Medical Association.
Symonds, C. P. (1928). Observations on the differential diagnosis and treatment of cerebral states consequent upon head injuries. British Medical Journal, 2, 828-832.

Teasdale, G., and Jennett, B. (1974). Assessment of coma and impaired consciousness. A practical scale. Lancet, 2, 81-84.

Teasdale, G., Jennett, B., and Knill-Jones, R. (1974). Assessing and recording 'conscious level'. Journal of Neurology, Neurosurgery, and Psychiatry, 37, 1286.

Trotter, W. (1924). On certain minor injuries of the brain. Lancet, 1, 933-939. 